\title{
Nöroşirurji Yoğun Bakım Ünitesinde Ateş Kontrolünde Uygulanan Hemşirelik Girişimleri
}

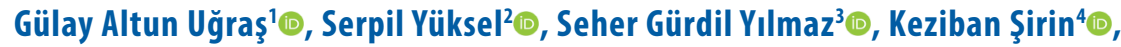 \\ Yüksel Turan ${ }^{5} \odot$, Selin Eroğlư ${ }^{6}$
}

'Mersin Üniversitesi, Hemşirelik Fakültesi, Cerrahi Hastalıkları Hemşireliği Anabilim Dalı, Mersin, Türkiye

${ }^{2}$ Necmettin Erbakan Üniversitesi Sağlık Bilimleri Fakültesi, Hemşirelik Bölümü Cerrahi Hastalıkları Hemşireliği Anabilim Dalı, Konya, Türkiye

${ }^{3}$ Mersin Üniversitesi Hemşirelik Fakültesi, Cerrahi Hastalıkları Hemşireliği Anabilim Dalı, Mersin, Türkiye

${ }^{4}$ İstanbul Üniversitesi Cerrahpaşa Tıp

Fakültesi, Nöroşiruriji Anabilim Dalı

Nöroşirurji Servisi, İstanbul, Türkiye

5̇stanbul Üniversitesi Cerrahpaşa Tıp

Fakültesi, Nöroşirurji Anabilim Dalı

Yoğunbakım Ünitesi, İstanbul, Türkiye

${ }^{6}$ istanbul Üniversitesi Cerrahpaşa Tıp

Fakültesi, Nöroşirurji Anabilim Dalı

Yoğunbakım Ünitesi, İstanbul, Türkiye

Gülay Altun Uğraş, Dr. Öğr. Üyesi

Serpil Yüksel, Dr. Öğr. Üyesi

Seher Gürdil Yılmaz, Öğr. Gör.

Keziban Şirin, Hemş. Hizm. Sorumlusu

Yüksel Turan, Hemşire

Selin Eroğlu, Hemşire

İletişim:

Dr. Öğr. ÜyesiGülay Altun Uğraş

Mersin Üniversitesi, Hemşirelik Fakültesi,

Cerrahi Hastalıkları Hemşireliği Anabilim Dalı,

Mersin, Türkiye

Tel: +90 $3243610001 / 4224$

E-Posta: gulay.altun@yahoo.com

Gönderilme Tarihi : 19 Temmuz 2017

Revizyon Tarihi : 17 Ekim 2017

Kabul Tarihi : 26 Ekim 2017
ÖZET

Giriş-Amaç: Bedenin önemli savunma mekanizmalarından biri olan ateş, nöroşirürji hastalarında metabolik aktiviteyi hızlandırarak, kafa içi basınç (KiB) artışına neden olmakta ve iyileşme sürecini olumsuz etkilemektedir. Literatürde, nöroşirürji hastalarında ateş kontrolünün, ateşe bağlı gelişebilecek sorunların önlenmesinde etkili olduğu bildirilmektedir.

Gereç-Yöntem: Retrospektif tanımlayııı tipteki bu araştırma, bir üniversite hastanesinin Nöroşirürji Yoğun Bakım Ünitesi'nde (NYBÜ), en az bir hafta yatan ve aksillar beden sıcaklığı $>38^{\circ} \mathrm{C}$ olan, 18 yaş ve üzeri 72 hasta dosyası incelenerek gerçekleştirildi. Araştırmanın uygulanabilmesi için ilgili kurumdan ve yerel etik kuruldan yazııı izin alındı. Veriler, Eylül 2013-Şubat 2014 tarihleri arasında araştırmacılar tarafından geliştirilen veri toplama formuyla toplandı. Veri analizinde; tanımlayıı istatistiksel yöntemler (frekans, ortalama, standart sapma) kullanıldı.

Bulgular: NYBÜ'nde 2010- 2014 yılları arasında en az 1 hafta yatan 180 hastadan 72'sinde (\%40) ateş oluştuğu saptandı. Ateş kontrolünü sağlamak amacıyla hemşireler tarafından uygulanan başısı girişimlerin, hekim istemi ile antipretik ilaç tedavisi uygulama $(\% 98,6)$, fan/vantilatör kullanma $(\% 88,9)$, Ilık silme banyo verme $(\% 75)$ ve odanın sıcaklığını ayarlama/battaniyeleri uzaklaştırma $(\% 72,2)$ olduğu belirlendi. En sık kullanılan antipretik ilaçların, metamizol sodyum $(\% 27,8)$, metamizol sodyumasetaminofen kombinasyonu $(\% 26,4)$ ve asetaminofen $(\% 16,7)$ olduğu saptandı.

Sonuç: Araştırmadan elde edilen verilere göre, NYBÜ'nde yatan hastalarda ateş kontrolünü sağlamak amacıyla en yaygın kullanılan yöntemin farmakolojik tedavi olduğu, en sık uygulanan hemşirelik girişimlerinin de, fiziksel soğutmayı sağlayan yöntemler olduğu saptandı.

Anahtar sözcükler: Ateş, nöroşirurji yoğun bakım ünitesi, hemşirelik girişimleri, fiziksel soğutma yöntemleri

\section{NURSING INTERVENTIONS TO CONTROL FEVER IN A NEUROSURGICAL INTENSIVE CARE UNIT}

\section{ABSTRACT}

Introduction: Whilst fever is one of the key defence mechanisms of the body, it also causes raised intracranial pressure (ICP) by accelerating metabolic activity in neurosurgical patients and adversely affects the healing process. In the literature, fever control in neurosurgical patients is reported to be effective in preventing adverse consequences arising from uncontrolled fever.

Material and Methods: This study employs a retrospective descriptive methodology. It was undertaken by examining a sample of medical records for 72 patients. All were over 18 years of age, had remained in the Neurosurgical Intensive Care Unit of a University Hospital for at least one week and had a recorded axillary temperature exceeding $38^{\circ} \mathrm{C}$. Written permission from the Ethics Committee of the relevant institution was obtained to allow the research to proceed. Data were gathered between September 2013 and February 2014 using a data collection form developed by the researchers. Descriptive statistical methods (frequency, average, standard deviation) were used for the data analysis.

Results: 72 out of 180 (40\%) patients admitted to NICU between 2010 and 2014 developed a fever. The principal interventions by nurses to maintain fever control were identified as: giving an antipyretic agent by doctor's order (98.6\%), using a cooling electrical fan $(88.9 \%)$, giving a tepid bed bath $(75 \%)$ and adjusting the room temperature or removing blankets $(72.2 \%)$. The most frequently used antipyretic agents were identified as metamizole sodium (27.8\%), a combination of metamizole sodium and paracetamol $(26.4 \%)$ or paracetamol alone $(16.7 \%)$.

Conclusion: From the study data, it was determined that the most frequent method used to provide fever control in NICU patients was pharmacological, and that the most frequently used nursing interventions were attempts at physical cooling.

Keywords: Fever, neurosurgical intensive care unit, nursing interventions, physical cooling methods. 
B eden sıcaklığı; metabolik aktivite ile üretilen Isı ile dış çevreye olan ısı kaybı arasındaki denge olup, normal değerleri $36-37,7^{\circ} \mathrm{C}^{\prime}$ dir (1). Amerikan Nörolojik Bilimler Hemşireleri Derneği (American Association of Neuroscience Nurses-AANN), beden sıcaklığının $38.0^{\circ} \mathrm{C}$ 'den yüksek olmasını, ateş olarak kabul etmektedir (2). Nöroşirürji hastalarında ateş, nörolojik yaralanma sonrası ilk birkaç hafta içerisinde yaygın görülen bir sorundur (3-6). Nöroşirürji yoğun bakım ünitesi (NYBÜ) hastalarında ateş görülme oranı \%22-83 olup (7-9), bu oran subaraknoid kanamalarda (SAK) \%65, travmatik beyin yaralanması (TBY) sonrası \%40, intrakraniyal kanamalarda ise \%31'dir (7).

Nöroşirürji hastalarında ateş görülme nedenleri, enfeksiyon ve enfeksiyon dışı faktörler olmak üzere ikiye ayrılabilir. Enfeksiyon dışı faktörlerden en önemlisi, TBY nedeniyle hipotalamusta bulunan termoregülatör merkezin hasarlanması$\operatorname{dır}(4,5,10-13)$. Ateş oluşumunda etkili diğer önemli faktörler, SAK sonrası, subaraknoid alanda biriken kan, kan ürünleri $(3,11)$ ve sonraki süreçte gelişen vazospazmdır (4). Ayrıca, oluşabilecek nöbetleri önlemek amacıyla kullanılan fenitoin sodyum etken maddesine sahip antikonvülsan ilaçlar $(3,14,15)$, atelektazi, pulmoner emboli, derin ven trombozu, dehidratasyon, ilaç reaksiyonları ve kardiyak sorunlar da ateşe neden olabilir. Endotrakeal entübasyon ve aspirasyonla ilişkili nazokomiyal pnömoni, sıvı replasmanı, santral venöz basınç ölçümü, intraarteriyel kan basıncı izlemi ve saatlik idrar takibi amacıyla yerleştirilen kateterler de enfeksiyona neden olarak ateş oluşma riskini artırmaktadır $(3,14,16,17)$.

Nöroşirürji hastalarında görülen ateş, YBÜ'inde ve hastanede kalış süresinde uzamaya, kafa içi basınç (KIB) artışına, Glaskow Koma Skala Puanında (GKS) düşüşe, hemodinamik parametrelerde ve fonksiyonel durumda bozulma gibi istenmeyen sonuçlara ve yaşam kaybına neden olabilmektedir $(5-8,10,12,15,18)$. Ayrıca ateş, metabolizmayı hızlandırarak, glutamat salınımını, serbest radikallerin üretimini ve kan-beyin bariyerinin geçirgenliğini artırarak, serebral ödeme neden olur ve beyin üzerinde olumsuz etkiler oluşturur $(12,19)$. Beden sıcaklığındaki her $1^{\circ} \mathrm{C}$ 'lik artış, serebral kan akımını \%5-6, metabolik gereksinimi \%10 (20), KiB'ı ise 3-4 $\mathrm{mmHg}$ artırarak(8) nöroşirürji hastalarında ikincil yaralanmaların oluşumuna neden olmaktadır (11-13). Ateşin nöroşirürji hastalarının hemodinamik parametreleri üzerindeki etkisinin incelendiği bir araştırmada, ateşin nabız sayısında artışa; sistolik kan basıncı ve arteriyel oksijen saturasyonunda azalmaya neden olduğu bulunmuştur (17). TBY'lı hastalarda ateşin hasta sonuçlarına etkisinin incelendiği benzer bir çalışmada, beden sıcaklığı arttıkça $\left(38-39^{\circ} \mathrm{C}\right.$ den $\left.\geq 39^{\circ} \mathrm{C}\right)$, mortalite oranının \%20'den \%45,5'e; istenmeyen sonuçların ise $\% 56,2$ 'den \%73,3'e yükseldiği saptanmıştır (5).
Yapılan çalışmalar, beden sıcaklığını normal sınırlarda sürdürmenin klinik sonuçları olumlu etkilediğini ortaya koymuştur (5,11-13,20,21). Ateş, nöroşirürji hastalarında da istenmeyen sonuçlara ve yaşam kaybına neden olduğundan, bu hasta grubunda beden sıcaklığının normal sınırlarda sürdürülmesi önemlidir $(18,22)$. Yoğun bakım hemşirelerinin, hastalarda komplikasyon gelişimine neden olabilecek ateşin fizyolojik etkilerini bilmeleri, bu etkileri ve beden sıcaklığını doğru ve dikkatle izlemeleri; beden sıcaklığının normal sınırlarda sürdürülmesini sağlayacak girişimleri komplikasyonlar gelişmeden uygulamalarını sağlayacaktır $(17,25)$. Nöroşirurji hastalarının ateş kontrolünde hemşireler, hekim istemi doğrultusunda oral ya da intravenöz yolla farmakolojik tedaviyi (asetominofen, parasetamol, diklofenak vb.) uygulamakta $(9,19,24)$ ve farmakolojik tedavi ile birlikte ya da tek başına fiziksel soğutma yöntemleri gibi farmakolojik olmayan yöntemleri kullanmaktadır $(5,9,12,15,24-27)$. $\mathrm{Bu}$ araştırmada da nöröşirürji hastalarında istenmeyen sonuçlara neden olabilecek ateşin kontrolünde, yoğun bakım hemşirelerinin uyguladıkları hemşirelik girişimlerini belirlemek amaçlandı.

\section{Gereç-yöntem}

Araştırmanın tipi

Araştırma, retrospektif tanımlayıcı tiptedir.

\section{Araştırmanın yeri, evreni ve örneklemi}

Araştırma, İstanbul'da bir üniversite hastanesinin NYBÜ'nde gerçekleştirildi. Araştırmanın evrenini, 20102014 yılları arasında bu NYBÜ'nde en az bir hafta yatan 180 hasta, örneklemini ise aksillar beden sıcaklığı $>38^{\circ} \mathrm{C}$ olan 18 yaş ve üzeri 72 hasta oluşturdu.

\section{Veri toplama aracı ve verilerin toplanması}

Veriler, araştırmacılar tarafından literatür doğrultusunda oluşturulan $(5,10-12,21)$ ve iki bölümden oluşan veri toplama formu ile Eylül 2013- Şubat 2014 tarihleri arasında hasta dosyaları incelenerek toplandı. Veri toplama formunun birinci bölümünde; hastaların tanıtıcı özelliklerine (yaş, cinsiyet, tıbbi tanı, uygulanan cerrahi girişim vb.) ilişkin sorular, ikinci bölümünde ise; ateş kontrolünde uygulanan tedavi ve bakım girişimlerini belirlemeye yönelik sorular yer aldı.

\section{Verilerin analizi}

Elde edilen veriler bilgisayar ortamına aktarılarak, tanımlayıc istatistiksel yöntemler (frekans, ortalama, standart sapma) ile analiz edildi. 


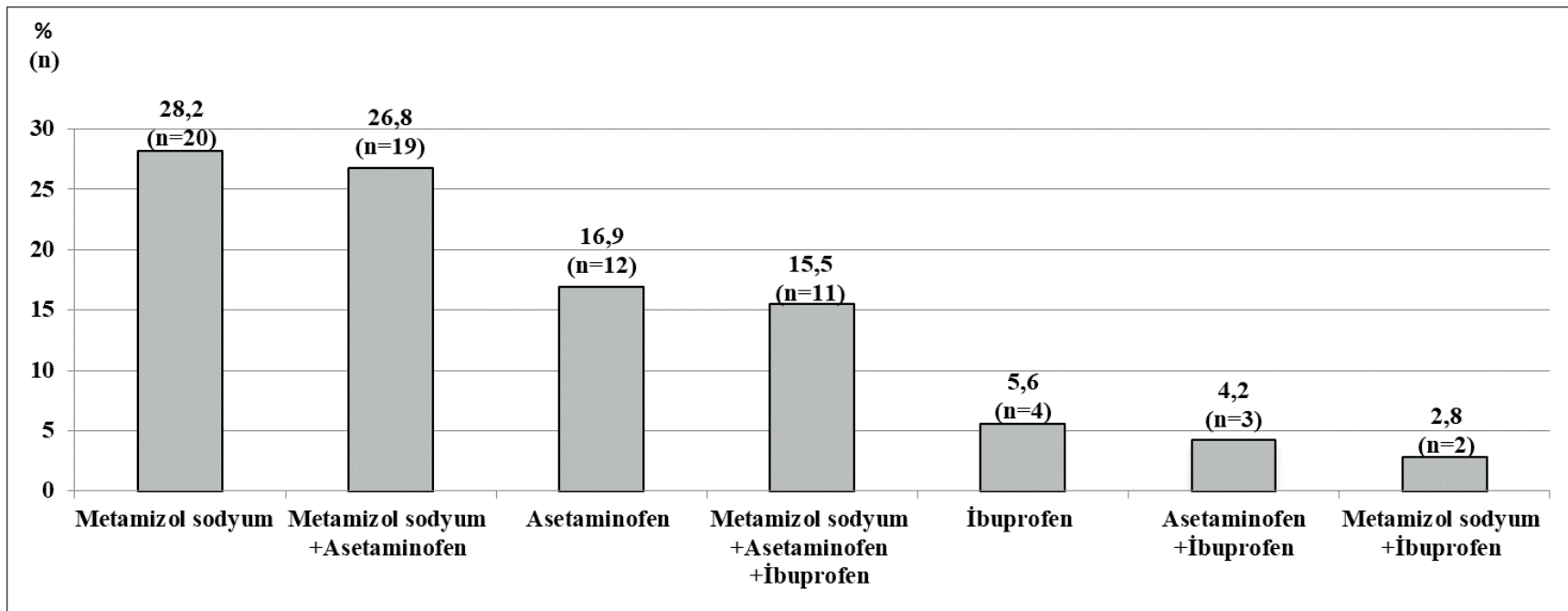

Grafik 1.

\section{Araştırmanın etik yönü}

Araştırmaya başlamadan önce, İstanbul Üniversitesi Cerrahpaşa Tıp Fakültesi Hastanesi Nöroşirürji Anabilim Dalı́ndan ve İstanbul Üniversitesi Cerrahpaşa Tıp Fakültesi Hastanesi Yerel Etik Kurulu'ndan yazılı izin alındı (Sayı: 83045809/18850; Tarih: 12.07.2013).

\section{Bulgular}

Nöroşirürji yoğun bakım ünitesinde, 2010-2014 yılları arasında en az 1 hafta yatan 180 hastadan 72'sinde (\%40) ateş oluştuğu saptandı. Ateş oluşan hastaların yaş ortalaması $56,82 \pm 16,78$ yıl (17-86 yıl) olup, \%66,7'si erkekti. Hastaların $\% 30,6$ 'sının beyin tümörü, $\% 29,1$ 'inin SAK ve $\% 26,4$ 'ünün kafa travması tanısıyla NYBÜ'nde yattığı saptandı. GKS puanı 3-8 arasında olanların çoğunlukta $(\% 38,9)$ olduğu belirlendi. Cerrahi girişim uygulananların $(\% 84,7 ; n=61)$ \%37,7'sine kitle eksizyonu, \%24,6'sına hematom boşaltılması, \%16,4'üne ise embolizasyon yapıldığı saptandı (Tablo 1).

Hekim istemi doğrultusunda ateş kontrolünde en yaygın uygulanan girişimin farmakolojik tedavi (antipretik ilaç) (\%98,6; n=71) olduğu, bir hasta dışında tüm hastalara farmakolojik tedavi uygulandığı belirlendi. Hastaların $\% 28,2$ 'sine metamizol sodyum, $\% 26,8$ 'ine asetaminofen ile metamizol sodyum, $\% 16,9^{\prime}$ una ise asetaminofen uygulandığı saptandı. (Grafik 1). Ateş kontrolünü sağlamak amacıyla hemşireler tarafından en sık uygulanan farmakolojik olmayan girişimlerin sırasıyla, fan/vantilatör kullanma $(\% 88,9)$, llık banyo/silme banyo uygulama (\%75) ve oda sıcaklığını ayarlama/battaniyeleri uzaklaştırma $(\% 72,2)$ gibi fiziksel soğutma yöntemleri olduğu, bu yöntemlerin farmakolojik tedavi ile birlikte uygulandığı belirlendi (Tablo
Tablo 1. Hastaların tanitıcı özellikleri $(n=72)$

\begin{tabular}{lcc} 
Tanıtıcı Özellikler & $\overline{\boldsymbol{x}}$ & $\boldsymbol{S S}$ \\
\hline Yaş ortalaması & 56,82 & 16,78 \\
Cinsiyet & $\mathrm{n}$ & $\%$ \\
Kadın & 24 & 33,3 \\
Erkek & 48 & 66,7
\end{tabular}

Tanı

Beyin tümörü $22 \quad 30,6$

Subaraknoid kanama $21 \quad 29,1$

Kafa travması $\quad 19 \quad 26,4$

Serebellar infarktüs $\quad 6 \quad 8,3$

Şant disfonksiyonu $\quad 4 \quad 5,6$

Glaskow Koma Skalası Puanı

3-8

38,9

9-12 $19 \quad 26,4$

$\begin{array}{lll}13-15 & 25 & 34,7\end{array}$

Cerrahi Girişim Uygulanma Durumu

$\begin{array}{lll}\text { Uygulandı } & 61 & 84,7\end{array}$

$\begin{array}{lll}\text { Uygulanmadı } & 11 & 15,3\end{array}$

Uygulanan Cerrahi Girişim*

$\begin{array}{lll}\text { Kitle eksizyonu } & 23 & 37,7\end{array}$

Hematom boşaltılması $\quad 15 \quad 24,6$

Embolizasyon $\quad 10 \quad 16,4$

Eksternal ventriküler drenaj $\quad 5 \quad 8,1$

Anevrizma klempleme $\quad 4 \quad 6,6$

Şant revizyonu $\quad 4 \quad 6,6$

*Cerrahi girişim uygulanan 61 hasta üzerinden sayı ve yüzde verilmiştir. 
2). Farmakolojik ve farmakolojik olmayan yöntemlerin uygulanmasından sonra, hastaların beden sıcaklığının subfebril aralıkta $\left(36-37.7^{\circ} \mathrm{C}\right)$ seyrettiği saptandı.

Tablo 2. Ateş kontrolünde uygulanan fiziksel soğutma yöntemleri

\begin{tabular}{lcc} 
Fiziksel soğutma yöntemleri* $^{*}$ & $\boldsymbol{n}$ & \% \\
\hline Fan/vantilatör kullanma & 64 & 88,9 \\
Ilık banyo/silme banyosu & 54 & 75,0 \\
Odanın sıcaklığını ayarlama/battaniyeleri uzaklaştırma & 52 & 72,2 \\
Buz paketi ile soğuk uygulama & 30 & 41,7 \\
Soğuk sıvılarla mesane irrigasyonu & 17 & 23,6 \\
Soğuk intavenöz sıvı infüzyonu & 10 & 13,9 \\
Nazogastrik tüpün soğuk sıvılarla irrigasyonu & 5 & 6,9 \\
Soğuk havlu yerleştirme/soğuk kıyafet giydirme & 5 & 6,9 \\
\hline *Birden fazla seçenek işaretlenmiş̧ıir & \multicolumn{2}{c}{}
\end{tabular}

\section{Tartışma}

Ateş, nöroşirurji hastalarında metabolik aktiviteyi hızlandırarak KIB artışına neden olduğundan ve iyileşme sürecini olumsuz etkilediğinden $(5-8,10,12,15,18,19)$, bu hasta grubunda beden sıcaklığının $36-37^{\circ} \mathrm{C}$ aralığında tutulması (normotermi) gerektiği vurgulanmaktadır (13). Beyin Travma Derneği (Brain Trauma Foundation) 2007 yılında yayınladığı rehberde, TBY'lı hastalarda normoterminin sürdürülmesini önermektedir (23). Hemşireler, ateş kontrolünde, asetominofen gibi farmakolojik yöntemler ile soğuk banyo, buz paket uygulama, soğutma battaniyesi ya da intravasküler soğutma araçları gibi farmakolojik olmayan fiziksel soğutma yöntemlerini ayrı ayrı ya da birlikte kullanılabilmektedir $(1,3,4,10,13,14,20)$.

Yapılan çalışmalarda, NYBÜ'sinde ateş görülme oranı \%2283 olarak belirtilmektedir (7-9). Benzer şekilde bu araştırmada, hasta dosyalarının incelendiği 2010-2014 yılları arasında NYBÜ'nde en az 1 hafta yatan180 hastanın 72'sinde (\%40) ateş oluştuğu belirlendi. Bu oran, TBY'। ' hastalarda saptanan ateşten (\%83) daha düşük olmakla birlikte bu çalışmadaki gibi farklı tanıya sahip nöroşirürji hastalarında yapılan bir çalışma (\%50) ile benzerlik göstermektedir (18). Diğer çalışmalara $(7,9,18)$ benzer olarak bu araştırmada da ateşin en sık görüldüğü tanıların beyin tümörü, SAK ve TBY olduğu belirlendi. Ancak, çalışmada hangi tanıda ateşin anlamlı olarak daha fazla görüldüğü belirlenemedi. Ateşin bu tanılara sahip hastalarda fazla görülmesinin nedeninin, hipotalamik termoregülatör merkezin hasarlanması $(4,5,10-13)$, SAK nedeniyle toplanan kan, kan ürünleri, vazospazm oluşumu $(3,4,11)$ ve nöbetleri önlemek amacıyla uygulanan antikonvülsan ilaçların yan etkisi olabileceği bildirilmiştir $(3,14,15)$.
Nöroşirürji hastalarında, ateşin yol açabileceği KiB artışı ve serebral ödem $(5,7,8,10,12,15,18)$ gibi ciddi komplikasyonları önlemek amacıyla, ateş kontrolünde çeşitli farmakolojik ajanlardan yararlanılmaktadır. Ateş oluşumuna hipotalamustaki prostaglandin artışı neden olduğundan, bu artışın önlenmesi ateş kontrolünde etkilidir. Prostoglandin sentezini engellemek amaciyla, antipiretikler ve steroid olmayan antiinflamatuvar (NSAi) ilaçlar kullanılmaktadır (15). Nöroşirürji hastalarına yönelik hazırlanan ateş kontrol protokollerinde, asetominofen kullanımı önerilmektedir (24). Avustralya ve Yeni Zelanda'daki 33 YBÜ'nde akut nörolojik lezyonu (inme, TBY vb.) olan hastaların beden sıcaklığının izlendiği bir çalışmada, hastaların yalnızca \%24'ünün hedeflenen beden sıcaklığında olduğu ve ateş kontrolünde yaygın olarak parasetamol kullanıldığı saptanmıştır (56\%) (9). Ateş kontrolü amacıyla asetominofen ya da diklofenak uygulanan hastalarda, beden sıcaklığının $39.1^{\circ} \mathrm{C}^{\prime}$ den $37.9^{\circ} \mathrm{C}^{\prime} \mathrm{ye}, \mathrm{KiB}^{\prime} ı \mathbf{n} 16$ mmHg'dan $12 \mathrm{mmHg}$ ya düştüğü bulunmuştur (19). Cerrahi YBÜ'inde yapılan bir çalışmada, ateş kontrolünde en sık uygulanan ilaçların metamizol sodyum ve asetaminofen olduğu belirlenmiştir (25). Bu çalışmada da, ateş kontrolü amacıyla bir hasta dışında tüm hastalara farmokolojik ajanların uygulandığı, en sık uygulanan farmakolojik ajanların literatüre benzer biçimde parasetamol özelliği gösteren ve birçok nöroşirürji hastasının ateş kontrol protokolünde kullanılan asetominofen ile NSAi özellikteki metamizol sodyum olduğu belirlendi.

Ateş kontrolünde farmakolojik ajanların yeterli olmadığı durumlarda, ilaç tedavisine ek olarak fiziksel soğutma yöntemlerinin kullanılması önerilmektedir (15). Nöroşirürji hastalarının ateş kontrolünde, asetominofen ile birlikte uygulanan fiziksel soğutma yöntemlerinin daha etkili olduğu bildirilmiştir (24). Puccio ve ark. (9), intavasküler soğutma kateterinin ateşi ve ateşle ilişkili intrakraniyal hipertansiyonu düşürmede etkili olduğunu saptamıştır. Bir çalışmada, hastaların \%25'inde fiziksel soğutma yöntemlerinin beden sıcaklığını \%32 oranında düşürdüğü bildirilmiştir (9). TBY'lı hastalarda asetominofen ile birlikte periferik soğutmanın uygulandığı hastalarda beden sıcaklığının $38.6^{\circ} \mathrm{C}^{\prime}$ den $36.3^{\circ} \mathrm{C}^{\prime}$ ye düştüğü, sistemik oksijen tüketiminin ise \%27 oranında azaldığı bulunmuştur (26). Bu çalışmada da, bir hasta dışında tüm hastaların ateş kontrolünde farmakolojik ajanlar ile birlikte fiziksel soğutma yöntemlerinin de uygulandığı belirlendi.

Nöroşirurji hemşireleri tarafından kullanılan farmakolojik olmayan ateş kontrol girişimlerinin değerlendirildiği çalışmalarda, en sık uygulanan yöntemlerin buz paketleri, soğuk su battaniyeleri, fanlar ve llık banyo gibi yöntemler 
olduğu bildirilmiştir $(5,12,24)$. Ikematsu (27), hemşirelerin ateş kontrolünde en sık soğutma yöntemlerini kullandığını; Çelik ve ark. (25), hemşirelerin en sık uyguladıkları soğutma yöntemlerinin ılık banyo, buz paketi ve ıslak çarşaf kullanımı olduğunu saptamıştır. Benzer şekilde bu çalışmada, ateş kontrolü amacıyla hemşirelerin en sık uyguladığı fiziksel soğutma yöntemlerinin sırasıyla; fan/vantilatör kullanımı, ılık silme banyo verme, odanın sıcaklığını ayarlama/battaniyeleri uzaklaştırma, buz paketi ile soğuk uygulama yapma olduğu belirlendi. Ek olarak çalışmada, Rockett ve ark. (12) tarafından sık uygulandığı belirtilen oda sıcaklığını değiştirme ve örtüleri/kıyafetleri uzaklaştırma gibi girişimlerin daha az sıklıkta uygulandığı da saptandı. Ayrıca, çalışmada hemşirelerin uyguladıkları soğuk sıvı infüzyonu, nazogastrik tüpün soğuk sıvılarla irigasyonu ya da soğuk sıvılarla mesanenin yıkanması gibi uygulamalara, daha önce yapılan çalışmalarda rastlanmamıştır $(5,12,27)$. Fiziksel soğutma yöntemlerini kullanan nöroşirürji hemşireleri, bu yöntemlerin cilt yoluyla ısı kaybını azaltan vazokonstrüksiyona yol açtığı; hızlı soğutmaya refleks yanıt olarak gelişen titremeye neden olarak metabolik gereksinimi, dolayısıyla da ikincil beyin yaralanması riskini artırdığı gerçeğini göz önünde bulundurmalıdır $(10,15)$. Araştırmada, hasta kayıtlarında fiziksel soğutma ile ilişkili herhangi bir olumsuz etki bildirimine rastlanmadı. Ancak, araştırmanın retrospektif olduğu göz önüne alındığında, fiziksel soğutmanın nöroşirürji hastalarındaki etkisinin prospektif çalışmalarla araştırılması hasta güvenliği açısından yararlı olabilir.

\section{Kaynaklar}

1. Fetzer SJ. Vital signs. In: P.A. Potter, A.G. Perry (Ed.), Fundamentals of Nursing.7th ed. St.Louis: Mosby Elsevier, 2009: 502-51.

2. American Association of Neuroscience Nurses (AANN) (2012). Nursing management of adults with severe traumatic brain injury. AANN Clinical Practice Guideline Series. Erişim adresi: http://www. aann.org/pubs/content/guidelines.html Erişim tarihi: 02.04.2019.

3. Marion DW. Controlled normotermia in neurologic intensive care. Crit Care Med 2004; 32: 43-5

4. Rabinstein AA, Sandhu K. Non-infectious fever in the neurological intensive care unit: incidence, causes and predictors. J Neurol Neurosurg Psychiatry 2007; 78: 1278-80. [CrossRef]

5. Li J, Jiang JY. Chinese Head Trauma Data Bank: Effect of hyperthermia on the outcome of acute head trauma patients. Journal of Neurotrauma 2012; 29: 96-100. [CrossRef]

6. Bohman, LE, \& Levine, JM. Fever and therapeutic normothermia in severe brain injury: an update. Current Opinion in Critical Care 2014;20: 182-8. [CrossRef]

7. Commichau C, Scarmeas N, Mayer SA. Risk factors for fever in the neurologic intensive care unit. Neurology 2003; 60: 837-41.

8. Elf K, Nilsson P, Ronne-Engström E, Howells T, Enblad P. Temperature disturbances in traumatic brain injury: relationship to secondary insults, barbiturate treatment and outcome. Neurological Research, 2008; 30: 1097-105. [CrossRef]

\section{Araştırmanın sınırlılıkları}

Araştırmanın ilk sınırlılığı, retrospektif olarak gerçekleştirilmiş olmasıdır. Verilerin kayıtlardan elde edilmiş olması, hekim isteminde yer almayan, hemşirenin bağımsız olarak uyguladığı ve kaydetmediği farmakolojik olmayan ateş kontrolü yöntemlerinin belirlenmesini engellemiş olabilir. Tanımlayıcı nitelikte bu araştırmada, hangi tanıda ateşin anlamlı oranda daha fazla görüldüğü, ateşe neden olan faktörler, ateşin nörolojik hasta sonuçlarına etkisi ve soğutma yöntemlerinin olumsuz etkisinin araştırılmaması da sınırlılıkları arasındadır.

\section{Sonuç}

Çalışmada, NYBÜ'ndeki hastaların yarısına yakınında ateş görüldüğü belirlendi. Ateşin nöroşirürji hastalarının iyileşme sürecindeki olumsuz etkileri göz önüne alındığında, bu hasta grubunda etkin ateş kontrolünün önemi ortaya çıkmaktadır. Çalışmada, nöroşirürji hemşirelerinin ateş kontrolünde literatürde de önerildiği gibi farmakolojik ajanlarla birlikte fiziksel soğutma yöntemlerini kullandığı saptandı. Bu çalışmada, hangi tanıda ateşin anlamlı oranda daha fazla görüldüğü, ateşe neden olan faktörler, ateşin nörolojik hasta sonuçlarına etkisi ve soğutma yöntemlerinin olumsuz etkisi araştırılmadı. Gelecek çalışmalarda bu konuların incelenmesi, nöroşirürji hastalarına özgü ateş kontrol protokollerinin geliştirilmesine rehberlik edebilir.

9. Saxena MK, Taylor CB, Hammond NE, Young PJ, Seppelt IM, Glass P, et al. Temperature management in patients with acute neurological lesions: an Australian and New Zealand point prevalence study. Crit Care Resusc. 2013; 15: 110-8.

10. Puccio AM, Fischer MR, Jankowitz BT, Yonas H, Darby JM, Okonkwo DO. Induced normothermia attenuates intracranial hypertension and reduces fever burden after severe traumatic brain injury. Neurocritical Care, 2009; 11: 82-7. [CrossRef]

11. Madden LK, DeVon HA. A systematic review of the effects of body temperature on outcome after adult traumatic brain injury. J Neurosci Nurs 2015; 47: 190-03. [CrossRef]

12. Rockett $\mathrm{H}$, Thompson HJ, Blissitt P.A. Fever management practices of neuroscience nurses: what has changed?. J Neurosci Nurs 2015;47:66-75. [CrossRef]

13. Littlejohns L. Acute intracranial problems. In: SL. Lewis, L Bucher, MM Heitkemper, MM Harding (Eds.), Medical Surgical Nursing, Assessment and Management of Clinical Problems, 10th ed. St.Louis: Elsevier Saunders, 2017: 1314-67.

14. Kiekkas P, Sakellaropoulos GC, Brokalaki H, Manolis E, Samios A, Skartsani C, \& Baltopoulos GI. Nursing workload associated with fever in the general intensive care unit. Am J Crit Care 2008;17:522-31.

15. Meier K, Lee K. Neurogenic fever: review of pathophysiology, evaluation, and management. J Intensive Care Med 2017; 32: 124-9. [CrossRef] 
16. Cunha BA. Clinical approach to fever in the neurosurgical intensive care unit: Focus on drug fever. Surg Neurol Int 2013;4:318-22. [CrossRef]

17. Asgar Pour H, Yavuz M. Effects of fever on haemodynamic parameters in neurosurgical intensive care unit patients. Intensive and Crit Care Nurs 2014; 30: 325-32. [CrossRef]

18. Wang Z, Shen M, Qiao M, Zhang H, Tang Z. Clinical factors and incidence of prolonged fever in neurosurgical patients. J Clin Nurs 2016; 26: 411-7. [CrossRef]

19. Stretti F, Gotti M, Pifferi S, Brandi G, Annoni F, \& Stocchetti N. Body temperature affects cerebral hemodynamics in acutely brain injured patients: an observational transcranial color-coded duplex sonography study. Crit Care 2014; 18: 552. [CrossRef]

20. Altun Uğraş $G$, Yüksel $S$. Factors affecting intracranial pressure and nursing interventions. Jacobs Journal of Nursing and Care 2014;1:1-4.

21. Mathai K.I, Sudumbrekar S.M, Shashivadhanan M.S. Sengupta S.K, Rappai T.J. Decompressive craniectomy in traumatic brain injury rationale and practice. Indian J Neurotrauma 2010; 7: 9-12.
22. Thompson HJ, Kirkness CJ, Mitchell PH. Fever management practices of neuroscience nurses, part II: nurse, patient, and barriers. J Neurosci Nurs. 2007a; 39: 196-1.

23. Bratton SL, Chesnut RM., Ghajar J, McConnell Hammond FF, Harris $\mathrm{OA}$, Hartl R, et al. Guidelines for the management of severe traumatic brain. J Neurotrauma 2007; 24 (Suppl 1): 1-106.

24. Thompson HJ, Kirkness CJ, Mitchell PH, Webb DJ. Fever management practices of neuroscience nurses: national and regional perspectives. J Neurosci Nurs. 2007b; 39: 151-62.

25. Çelik S, Yıldırım I, Arslan I, Yıldırım S, Erdal F, Yandı YE. Hemodynamic and oxygenation changes in surgical intensive care unit patients with fever and fever lowering nursing interventions. Int J Nurs Pract 2011; 17: 556-61. [CrossRef]

26. Hata JS, Shelsky CR, Hindman BJ, Smith TC, Simmons JS, Todd MM. A prospective, observational clinical trial of fever reduction to reduce systemic oxygen consumption in the setting of acute brain injury. Neurocrit Care, 2008; 9: 37-44. [CrossRef]

27. Ikematsu $Y$. Characteristics of and interventions for fever in Japan. Int Nurs Rev, 2004; 51: 229-39. [CrossRef] 